\title{
The Impact of Service Quality on Patient Satisfaction in the Health Care System
}

\author{
Nazan Yashar Akbulut ${ }^{1}$, Karam Ali Oglah ${ }^{2}$ \\ ${ }^{1}$ University of Jordan Master Degree Studies in Total Quality Management \\ ${ }^{2}$ University of Jordan Master Degree in Engineering Project Management
}

\begin{abstract}
Objective: Quality of Care and patient satisfaction are major challenges faced by the healthcare sector in Jordan. This paper aims to study the factors affecting service quality on the Patient Satisfaction from patient's perspectives in Jordan. Method: Cross Sectional Survey. Population \& sample: The study sample consisted of (200) respondents in King Hussein Medical Centre Hospital. Measures: The collected data were analyzed using the SPSS package. Result: The study results revealed that quality of care has an impact on patient satisfaction. Moreover the results indicated that patients are satisfied with quality of care in the hospital. The study recommended that the hospital have to set up criteria for their quality provided for patients, and they are requested to provide sufficient number of qualifies medical staff to deal with the increased number of patients.
\end{abstract}

Keywords: Quality of Care, Patient Satisfaction. King Hussein Medical Centre Hospital

\section{Introduction}

This Study aims to measure the quality of health services in governmental hospitals from patient and clinic attendance experience and perspectives in Jordan; the study was conducted on the major teaching hospitals in Amman King Hussein Medical center.

Patients are not always satisfied with the care received in the hospitals; more attention needs to be paid to the specific needs and expectations of the patients, who make up the majority of attendance at many clinic departments. Nurses and physicians perceptions about good quality of care do not always agree with patients perceptions.

Health institution concept varied depending on the parties they deal with, and therefore each party defines it according to the relationship between them , but in order to avoid this variance it will be defined according to functional perspectiveso health institute is : a collection of specialists, medical professionals, non-medical and material inputs that organized in a certain pattern in order to serve the existing and potential patients and to satisfy their needs and the continuation of health organization (Greer, S.L.et al 2004) [1].Health organization is also defined as social , and human institution, designed to achieve specific objectives and consistsof professionals and specialists individuals in various health and medical fields offer a variety of health care (Bonfrer, I.et al)[2]. These definitions are focusing on traditional function of the health institutions as a place to treat patients and modern concept as an integral part of the social system, the performance of various health functions.

\section{Literature Review}

Aiken, et al (2012)[3]study aimed to determine whether hospitals with a good oorganization of care can affect patient care and nurse workforce stability in European countries, Cross sectional surveys of patients and nurses were used, nurses were surveyed in general acute care hospitals (488 in 12European countries; 617 in the United States); patients were surveyed in 210 European hospitals and 430 US hospitals. The participants were 33659 nurses and 11318 patients in Europe and 27509 nurses and more than 120000 patients in the US; in conclusion they found thatdefects in; hospital care quality which were common in all countries,defectsin Doctor-patient communication and quality of care.

JozienBensing(2002) [4] study aimed to compare between three independent sources of assessment of medical consultations. A panel of 12 experienced general practitioners rated 103 consultations with hypertensive patients on the quality of psychosocial care. Two contrasting groups were formed: consultations that were rated high and those rated low in quality of psychosocial care. Knowledge about doctor-patient communication proved to predict very well as to which quality group the consultations belonged. A very high percentage $(95 \%)$ was predicted accurately.

(van Campen, et al, 1995) [5]study aimed to survey the literature on the assessment of quality of care from the patient's perspective; the concept has often been operationalized as patient satisfaction. Quality of care from the patient's perspective, however has been investigated only very recently and only a few measuring instruments have explicitly been developed for the assessment of quality of care from the patient's perspective. The studies consider patient satisfaction as an indicator of quality of care from the patient's perspective. This review is concerned with the question of whether any reliable and valid instruments have been developed to measure quality of care from the patient's perspective.

(Wolf, Debra.et al 2008)[6]study aimed to examine whether patient-cantered care (PCC) impacts patient satisfaction, perception of nursing care, and quality of care. A clinical randomized study (post-test design) was conducted; Differences were seen in 2 of 3 subscales within the Baker and Taylor Measurement Scale. The PCC group rated satisfaction $(\mathrm{P}=.04)$ and quality of services $(\mathrm{P}=.03)$ higher than controls. 


\section{International Journal of Science and Research (IJSR) \\ ISSN (Online): 2319-7064}

Index Copernicus Value (2016): 79.57 | Impact Factor (2015): 6.391

(SayedSaad Andaleeb2001) [7]study aimed to investigate 'Patients' perceptions about health services, therefore, patient-centred and identifies the service quality factors that are important to patients; it also examines their links to patient satisfaction in the context of Bangladesh. A field survey was conducted.

(M. Susan Marquis, et al 1983)[8] studyaimed to test the hypothesis that provider continuity and can be modelled as onebehavioural consequence of patient satisfaction. Bivariate and multivariate analyses (controlling for sociodemographic characteristics, prior use of services, health status, and health insurance plan) supported hypotheses. A multivariate linear probability function indicated that a 1point decrease on a general satisfaction scale was associated with a 3.4 percentage-point increase in the probability of provider change.

(Zastowny, Thomas R.et al1995)[9]study aimed to discuss the use of patient satisfaction and personal health care experiences as a measure of health care quality;it also presents a field-proven patient experience and satisfaction assessment methodology known as the Patient Experience Survey (PES) that has been employed throughout the country for the last decade. Finally, it offers recommendations and comments on the use of patient satisfaction data in quality assessment and improvement.

(Mosad Zineldin2006)[10] studyaimed to examine the major factors affecting patients' perception of cumulative satisfaction and to address the question whether patients in Egypt and Jordan evaluate quality of health care similarly or differently. The study concerns three hospitals in Egypt and Jordan. A questionnaire form was designed to achieve the research objectives. Findings: Patients' satisfaction with different service quality dimensions is correlated with their willingness to recommend the hospital to others. Continuity of care in general practice: effect on patient satisfaction.

(P. Hjortdahl, E. Laerum'1992)[11]studyaimed to evaluate the influence of continuity of care on patient satisfaction with consultations. Representative samples of 3918 Norwegian primary care patients were asked to evaluate their consultations by filling in a questionnaire. The response rate was $78 \%$. MAIN OUTCOME MEASURESThe patient's overall satisfaction with the consultation was rated on a six point scale. Results, Personal, continuous care is linked with patient satisfaction. If patient satisfaction is accepted as an integral part of quality health care, reinforcing personal care may be one way of increasing this quality.

(Masood A. Badri2009)[12] study aimed to present a comprehensive structural equation based service quality and patient satisfaction model taking into account the patient's condition before and after discharge. Data were collected using questionnaires .Results; the study highlights the importance of healthcare quality as patient satisfaction predictors by capturing other effects such as patient status.

\section{Research Problem}

After reviewing different literature,the most consistent finding suggests that; the more personal care will result in better communication and more patient involvement and hence better quality of care,the research problem was formulated in three questions:

1) How can Quality of care in the public hospitals impact on patient satisfaction?

2) Are the patients capable of assessing the quality of care?

3) How patient satisfaction can be measured?

\section{Research Objective}

The main objective of this study is to provide health service of distinguished quality that achieve patient satisfaction and increase communication channels between service users and providers in the public hospitals. Enable health organizations to perform their tasks efficiently and effectively to achieve better levels of productivity, since reaching the required level of health care provided is the main objective of quality implementation.Obtaining patient satisfaction, since there are core values of quality management to be offered in any health organization working to improve the quality and seeks to implement quality systems and consequently improve the performance of the work, and ultimately obtain patient satisfaction.

\section{Research Importance}

The research importance reflects the researcher concern about comparing the overall patient satisfaction with quality of provided services taking into consideration the small number of similar studies in the literature ( according to the researcher knowledge). The theoretical importance of this study lies in the study data which would help other researchers in their future studies, on the other hand the results of this study are important for hospital administrators when they are looking to bridge the gabs in order to improve the quality of services and positively affecting the overall patients satisfaction.

\section{Research Limitation}

Although the research has reached its aims, there were some unavoidable limitations.First, because of the time limit, this research was conducted on the patients attending ENT clinics in King Hussein medical centre during the period 2016-2017 and it was limited to Amman city. Second limitation was educational level, some patients were illiterate and needs help to answer the questionnaire, also accessing to patients in the both hospitals was limited and hard .

\section{Theoretical Framework}

Definitions and aspects of the concept of patient satisfaction and its impact on the quality of care are reviewed and integrated into a framework that views quality of care in ENT clinic dimensions impact of the patient satisfaction. Indicators are suggested for the measurement of the various relevant aspects of access, with the system and population descriptors seen as process indicators and satisfaction as outcome indicators in a theoretical model of the access concept.

\section{Volume 6 Issue 12, December 2017}


International Journal of Science and Research (IJSR)

ISSN (Online): 2319-7064

Index Copernicus Value (2016): 79.57 | Impact Factor (2015): 6.391

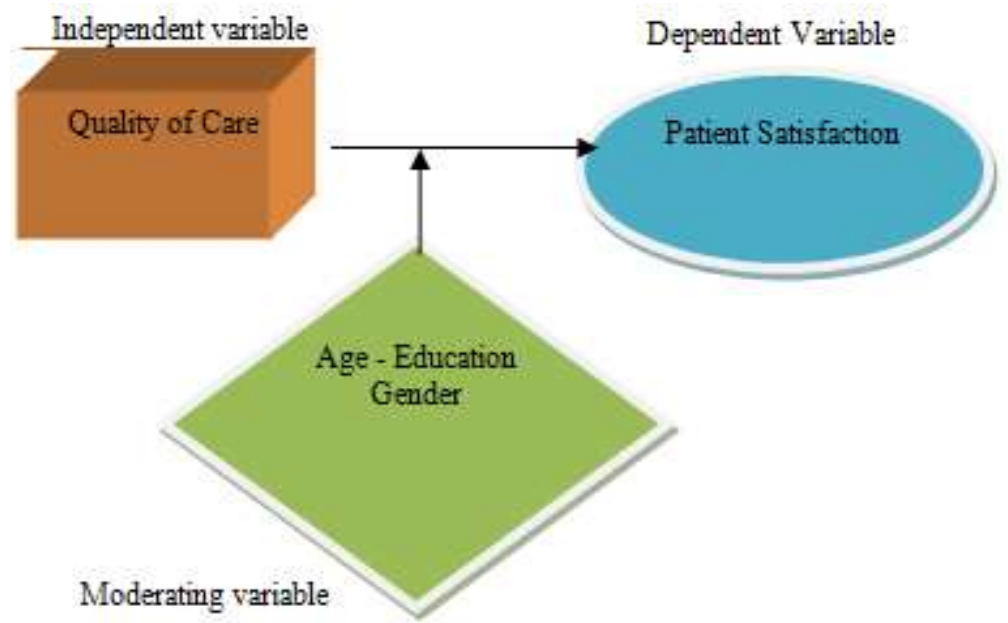

Theoretical Framework model (1)

Dimension \& Element of the Quality of Care in ENT Clinic model (2)

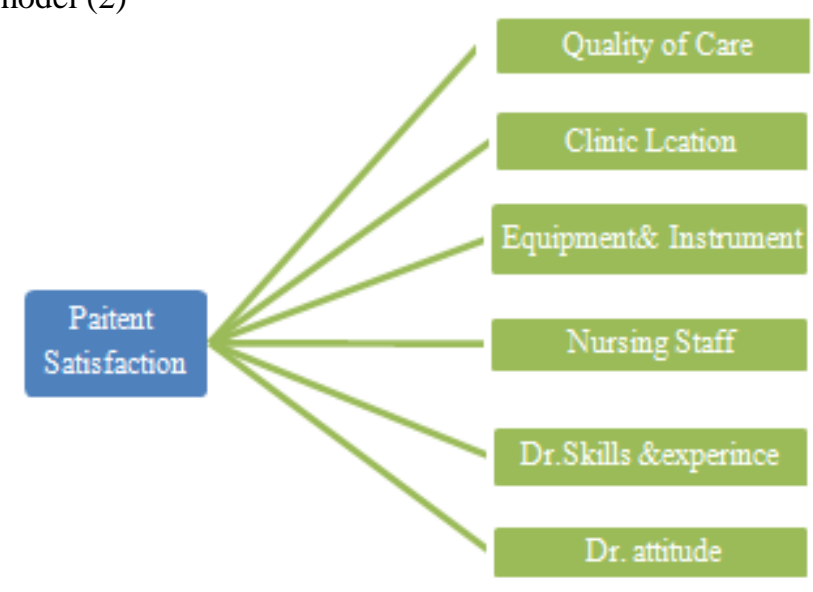

\section{Research Hypotheses}

The study is based on the following hypotheses;

\section{First Main hypothesis:}

$\mathrm{H} 0=$ There is nostatically significant impact at $(\alpha=0.05)$ level of Quality of Care on Patient Satisfaction.

\section{Sub Hypotheses;}

H0.1 $=$ There is no statically significant impact at $(\alpha=0.050)$ level of Clinic Assessment on Patient Satisfaction.

H0.2 $=$ There is no statically significant impact at $(\alpha=0.050)$ level of Instrument \& Equipment Assessment and Patient Satisfaction.

$\mathrm{H} 0.3=$ There is no statically significant impact at $(\alpha=0.050)$ level of NursingAssessment on Patient Satisfaction.

$\mathrm{H} 0.4=$ There is no statically significant impact at $(\alpha=0.050)$ level of physician Assessmenton Patient Satisfaction.

\section{Second Main Hypothesis;}

There are no statically significant differences ofimpact at $(\alpha=0.050)$ level quality care and Patient Satisfaction due to demographic variables(Gender, age and education level).

\section{Operational Definition}

Health Care Quality Definition; Service quality is defined as the "difference between predicted, or expected, service (customer expectations) and perceived serviced (customer perceptions). (Aagja and Garg, 2010)[13]. Patient
Satisfaction Definition; Patient satisfaction is defined as "the judgment made by patients on their expectations for care services that have been met or not in respect of both technical and interpersonal care" (Esch et al., 2008).[14]

\section{Research Methodology \\ Population and Sample;}

The study population consisted of all patients attending ENT clinic in King Hussein medical centre; one hundred patients were selected randomly from hospital during the period from October 10th to November 20th 2016. 220questionnaires were distributed,208 questionnaires werecollectedand eightquestionnaireswere notdisregarded because they were incomplete. So thestudy consisted of 200 patients and the response rate was $(90.1 \%)$.

\section{Data collection Methods:}

This researchbuilt over two basic source of information as following;

Primary source: The study usedquestionnaire to collect the needed data from studysample subjects.

Secondary Source: The study used books, articles, references, dissertations and the internet for building the theoretical part of the study.

The questionnaire was developed to collect the primary data. It was made up of 3 different sections. Section (1)includes respondents demographic information s such as (age, gender, and educational level,) . Section (2) had items related to care quality, precisely care quality dimensions (clinic, equipment, nursing and physician ). The last section concentrated on patient satisfaction. All of that used a 5point Likert Scale, with a value of: (1-Strongly Disagree, 2Disagree, 3-Neutral, 4-Agree and 5-Strongly Agree).

The questionnaire translated to Arabic language for patients whodidn't master English language. Participation in the study was voluntary and based on patientability to answer the questionnaire, the study pointed out that patienttends to be honest when they feel they might be identified or their care may be jeopardize.

\section{Data Analysis Method}

All collected data coded and analyzed using SPSS package, Different statistical technique will used such as descriptive

\section{Volume 6 Issue 12, December 2017}




\section{International Journal of Science and Research (IJSR) \\ ISSN (Online): 2319-7064}

Index Copernicus Value (2016): 79.57 | Impact Factor (2015): 6.391

analysis, to describe sample characteristic MEAN, and STANDAR DIVIATION forsubject'sresponses.T.TEST and other test will be used for testing the study hypotheses.

\section{Unite Of Analysis \& Time Horizon.}

Unit analysis includes all patients of King Hussein Medical Centre.Population based cross sectional study. Two hundred patients were selected randomly from hospital during the period from October 10th to November 20th (2016-2017).

\section{Statistical Analysis}

\section{Validity}

The questionnaire will be sent to university professorsand some specialists to express their opinion regarding the statement suitability on belonging to the topic; there comments will be taking in consideration either for cancelling ofor adding some statements for the purpose of formulating the final version of the questionnaire.

\section{Reliability}

Reliability of the questionnaire was tested using Cronbach's alpha, which checks whether items within the questionnaire measures the same concept.

Table 1: Instrument Reliability

\begin{tabular}{|c|c|c|c|}
\hline \multicolumn{2}{|c|}{ Variables } & $\begin{array}{c}\text { Cronbach } \\
\text { alpha }\end{array}$ & $\begin{array}{c}\text { No. of } \\
\text { items }\end{array}$ \\
\hline \multirow{3}{*}{$\begin{array}{c}\text { Independent } \\
\text { variables }\end{array}$} & Clinic Assessment & 69.7 & 6 \\
\cline { 2 - 4 } & Instruments and Equipment & 74.6 & 3 \\
\cline { 2 - 4 } & Nursing Assessment & 89.1 & 3 \\
\cline { 2 - 4 } & Physician Assessment & 79.2 & 7 \\
\hline Dependent Variables & Patient Satisfaction & 90.2 & 3 \\
\hline \multicolumn{2}{|r|}{ Total Instrument } & 89.4 & 22 \\
\hline
\end{tabular}

- Table No.1indicates that instrument reliability was $89.4 \%$, while the instrument's dimensions reliability ranges between $69.7 \%$ - 90.2\%. All values are more than 60\%.This means According to Sekaran, 2012[15]that the instrument is reliable and can be used for the purposes of this research.

\section{Data Presentation and Description}

The section aims to analyze the collected data through the questionnaire. Subjects were asked to answer the questionnaire based on their own experience. The obtained results were as follows:

Characteristic of the Respondents: the analysis for the collected data by self-administrated questionnaire revealed the results indicated in table (2) in terms of sample's age, education, and gender.

Table 2: Sample distribution according to Demographic information

\begin{tabular}{|c|c|c|c|}
\hline Variable & \multirow{2}{*}{ Options } & \multicolumn{2}{|c|}{ King Hussein Medical Centre } \\
\cline { 3 - 4 } & & Frequency & $\%$ \\
\hline \multirow{3}{*}{ Age } & $18-24$ & 10.0 & 10.0 \\
\cline { 2 - 4 } & $25-34$ & 24.0 & 24.0 \\
\cline { 2 - 4 } & $35-44$ & 22.0 & 22.0 \\
\cline { 2 - 4 } & $45-54$ & 28.0 & 28.0 \\
\cline { 2 - 4 } & $55+$ & 16.0 & 16.0 \\
\hline Education & Less than Secondary & 38.0 & 38.0 \\
\cline { 2 - 4 } & Secondary Certificate & 24.0 & 24.0 \\
\hline
\end{tabular}

\begin{tabular}{|c|c|c|c|}
\hline \multirow{4}{*}{} & Diploma & 16.0 & 16.0 \\
\cline { 2 - 4 } & BSC & 20.0 & 20.0 \\
\cline { 2 - 4 } & Master & 2.0 & 2.0 \\
\cline { 2 - 4 } & PhD Student & & \\
\hline Gender & Male & 58.0 & 58.0 \\
\hline & Female & 42.0 & 42.0 \\
\hline
\end{tabular}

- TableNo.2. Indicates that $10 \%$ of the sample (King Hussein Medical Centre) their age ranged between (1824), $24 \%$ ranged between (25-34) years, $22 \%$ ranged between (35-44) years, 28\% ranged between (45-54) years and finally $16 \%$ are 55 years and more.

- As for education level $38 \%$ of the sample has less than secondarym $24 \%$ have secondary certificate, $16 \%$ have diploma, 20\% have BSC and $2 \%$ have master.

- With regard to gender $58 \%$ of the sample were males and the rest $42 \%$ are females.

\begin{tabular}{|c|c|c|c|c|}
\hline No. & Statements & \multicolumn{3}{|c|}{ King Hussein Medical } \\
\cline { 3 - 5 } & & Mean & $\begin{array}{c}\text { S } \\
\text {.Deviation }\end{array}$ & Rank \\
\hline 3 & $\begin{array}{c}\text { Clinic Location Accessible } \\
\text { \&Convenient }\end{array}$ & 3.46 & .947 & 1 \\
\hline 4 & Clinic Is Clean \& Tidy & 3.32 & .737 & 2 \\
\hline 5 & $\begin{array}{c}\text { Sufficient \& Comfortable } \\
\text { Clinic furniture }\end{array}$ & 2.44 & .729 & 6 \\
\hline 6 & $\begin{array}{c}\text { Clinic Information } \\
\text { \&Appointment Desk was } \\
\text { helpful }\end{array}$ & 2.64 & .980 & 4 \\
\hline 7 & $\begin{array}{c}\text { Easy access to patient old } \\
\text { medical reports }\end{array}$ & 2.82 & 1.058 & 3 \\
\hline 8 & $\begin{array}{c}\text { Warm reception and tact in } \\
\text { dealing with patient }\end{array}$ & 2.48 & 1.105 & 5 \\
\hline & General Mean & 2.86 & 0.581 & \\
\hline
\end{tabular}

\section{Descriptive Statistics}

Table No.3Means and Standards Deviations for Sample Responses Regarding Clinic Assessment in General

- Table No.3 indicates the means and the standard deviations of the sample subjects.

- It indicates that means of King Hussein Medical Centre patients responses ranges between $(2.44-3.46)$ with medium

- Statement No. 3 "Clinic Location Accessible \&Convenient" ranked the first. while statement No.5 "Sufficient \& Comfortable Clinic furniture" ranked the last with respect to King Hussein Medical Centresample

- By reviewing the means the sample' responses, the researcher found that there is amedium agreement for all statements that measure clinic assessment.

Table 4: Means and Standards Deviations for Sample's Responses Regarding Medical Instruments and Equipment in the two hospitals

\begin{tabular}{|c|c|c|c|c|}
\hline \multirow{2}{*}{ No. } & Statements & \multicolumn{3}{|c|}{$\begin{array}{c}\text { King Hussein } \\
\text { Medical Centre }\end{array}$} \\
\cline { 3 - 5 } & & Mean & $\begin{array}{l}\text { Standard } \\
\text { Deviation }\end{array}$ & Rank \\
\hline 9 & Clinic has All Necessary Instrument & 3.16 & .861 & 2 \\
\hline 10 & Clinic Is Well Equipped & 2.98 & .710 & 3 \\
\hline 11 & Clean \& hygienic instrument & 3.44 & .756 & 1 \\
\hline & General Mean & 3.19 & 0.625 & \\
\hline
\end{tabular}




\section{International Journal of Science and Research (IJSR) \\ ISSN (Online): 2319-7064 \\ Index Copernicus Value (2016): 79.57 | Impact Factor (2015): 6.391}

- Table No.4 indicates the means and the standard deviations of the sample subjects.

- It indicates that means of King Hussein Medical Centrepatients responses ranges between $(2.98-3.44)$ with medium level .

- Statement No. 3 "Clean \& hygienic instrument $t$ " ranked the first, while statement No. 10 "Clinic Is Well Equipped" ranked the last .

- By reviewing themeans thesample responses, the researcher found that thereis amedium agreement for all statements that measure Instruments and Equipment.

Table 5: Means and Standards Deviations for Sample's Responses Regarding Nursing Assessment

\begin{tabular}{|c|c|c|c|c|}
\hline No. & Statements & \multicolumn{3}{|c|}{ King Hussein Medical } \\
\cline { 3 - 5 } & & Mean & $\begin{array}{c}\text { Standard } \\
\text { Deviation }\end{array}$ & Rank \\
\hline 12 & $\begin{array}{c}\text { Nursing Staff was } \\
\text { cooperative }\end{array}$ & 3.10 & 1.049 & 3 \\
\hline 13 & $\begin{array}{c}\text { Nursing Staff are } \\
\text { competent }\end{array}$ & 3.30 & 1.010 & 1 \\
\hline 14 & $\begin{array}{c}\text { Nursing Staff are } \\
\text { Skilled }\end{array}$ & 3.28 & .877 & 2 \\
\hline & General Mean & 3.23 & 0.900 & \\
\hline
\end{tabular}

- Table No.5 indicates the means and the standard deviations of the sample subjects.

- It indicates that means of King Hussein Medical Centrepatients responses ranges between $(3.10-3.28)$ with medium level .

- StatementNo.13 "Nursing Staff are competent"ranked the first, while statement No. 12 "Nursing Staff was cooperative" ranked the last .

- By reviewing themeans thesampleresponses, the researcher found that there is amedium agreement for all statements that measure nursing staff.

Table 6: Means and Standards Deviations for Sample's Responses RegardingPhysician in the clinic Assessment

\begin{tabular}{|c|c|c|c|c|}
\hline No. & Statements & \multicolumn{3}{|c|}{$\begin{array}{c}\text { King Hussein } \\
\text { Medical Centre }\end{array}$} \\
\cline { 3 - 5 } & & Mean & $\begin{array}{c}\text { Standard } \\
\text { Deviation }\end{array}$ & Rank \\
\hline 15 & $\begin{array}{c}\text { Doctors Behave well with the } \\
\text { patient }\end{array}$ & 3.90 & .835 & 4 \\
\hline 16 & $\begin{array}{c}\text { Doctor shows Respect for what } \\
\text { patient want to say }\end{array}$ & 3.98 & .710 & 1 \\
\hline 17 & $\begin{array}{c}\text { Doctor was able to diagnose patient } \\
\text { case }\end{array}$ & 3.98 & .651 & 1 \\
\hline 18 & Patient get enough time with doctor & 3.48 & .904 & 6 \\
\hline 19 & Patient Privacy Well Maintained & 2.82 & 1.20 & 7 \\
\hline 20 & $\begin{array}{c}\text { Doctor were able to give proper } \\
\text { management to Patient Case }\end{array}$ & 3.74 & .747 & 5 \\
\hline 21 & Doctors are well Qualified & 3.94 & .839 & 3 \\
\hline & General Mean & 3.69 & 0.564 & \\
\hline
\end{tabular}

- Table No. 6. indicates the means and the standard deviations of the samplesubjects.

- It indicates that means of King Hussein Medical Centrepatients responses ranges between $(2.82-3.98)$ with medium and high levels.

- Statements No.(16 and 17 ) "Doctor shows Respect for what patient want to say and Doctor was able to diagnose patient case" ranked the first by the King Hussein Medical Centresample, while Statement No. 19 "Patient Privacy Well Maintained 'ranked the .

- By reviewing themeans thesample' responses, the researcher found that there is a high agreement for all statements that measure physician in clinic.

Table 7: Means and Standards Deviations for Sample's Responses Regarding Patient Satisfaction

\begin{tabular}{|c|c|c|c|c|}
\hline No. & Statements & \multicolumn{3}{|c|}{$\begin{array}{c}\text { King Hussein } \\
\text { Medical Centre }\end{array}$} \\
\cline { 3 - 5 } & & Mean & $\begin{array}{c}\text { Standard } \\
\text { Deviation }\end{array}$ & Rank \\
\hline 22 & $\begin{array}{c}\text { I was overall satisfied with the } \\
\text { treatment }\end{array}$ & 3.12 & 1.131 & 1 \\
\hline 23 & $\begin{array}{c}\text { I would recommend this clinic to my } \\
\text { Relative \& Friends }\end{array}$ & 2.76 & 1.215 & 3 \\
\hline 24 & $\begin{array}{c}\text { Overall, the service you received } \\
\text { from the staff at clinic considered } \\
\text { good }\end{array}$ & 3.00 & 1.189 & 2 \\
\hline & General Mean & 2.96 & 1.098 & \\
\hline
\end{tabular}

- Table No.7 indicates the means and the standard deviations of the sample subjects.

- It indicates that means of King Hussein Medical Centrepatients responses ranges between $(2.76-3.12)$ with medium level .

- Statements No.11 "I was overall satisfied with the treatment" ranked the first, while statementNo.12 "I would recommend this clinic to my Relative \& Friends" ranked the last .

- By reviewing themeans the sampleresponses, the researcher found that thereis a high agreementfor all statements that measure patient satisfaction.

\section{Hypotheses Testing}

There is no statistically significant impact at significance level $(\alpha \leq 0.05)$ for quality with its dimensions (Clinic Assessment, Instruments and Equipment Assessment, Nursing Assessment and Physician Assessment) in King Hussein Medical Centre.

Table 8: Main Hypothesis Test results For King Hussein Medical Centre

\begin{tabular}{|c|c|c|c|}
\hline Variables & B & $(\mathrm{T})$ & Sig \\
\hline Clinic Assessment & .583 & 3.867 & .000 \\
\hline $\begin{array}{c}\text { Instruments and Equipment } \\
\text { Assessment }\end{array}$ & .145 & 1.152 & .252 \\
\hline Nursing Assessment & .278 & 3.013 & .003 \\
\hline Physician Assessment & .750 & 5.037 & .000 \\
\hline$(\mathrm{R})$ & \multicolumn{3}{|c|}{0.766} \\
\hline $\left.\mathrm{R}^{2}\right)$ & \multicolumn{3}{|c|}{36.042} \\
\hline F Calculated Value & \multicolumn{3}{|c|}{0.000} \\
\hline F Tabulated & \multicolumn{3}{|c|}{} \\
\hline Sig & & & \\
\hline
\end{tabular}

- Table No.8.Indicates the statistical test of this hypothesis.

- The table indicates that there is a statistically significant impact for quality onpatient satisfaction, since thesignificance level is $(0.00$.) $\mathrm{F}$ calculated value $=36.042$ which is more than the tabulated value (2.50). $\left(\mathrm{R}^{2}\right)$ value $=(0.603)$ indicates that quality interpret $(60.3 \%)$ of the change in patient satisfaction in the King 


\section{International Journal of Science and Research (IJSR) \\ ISSN (Online): 2319-7064}

Index Copernicus Value (2016): 79.57 | Impact Factor (2015): 6.391

Hussein Medical Centre. $\mathrm{R}$ value $=76.6 \%$ which represents a strong relationship between the variables, results of partial analysis for this hypothesis indicates that all dimensions except "Instruments and Equipment Assessment" impacts patient satisfaction such impact is clear through ( B) values (T) values at significant level (0.05) as described in the table.

- Based on the above, the Nullhypothesis isrejected and the alternative isaccepted, this means that there is a statistically significant impact at significance level $(\alpha \leq 0.05)$ for quality inKing Hussein Medical Centreon patient satisfaction.

First Sub-Hypothesis testing Results;

There is no statistically significant impact at significance level $(\alpha \leq 0.05)$ of Clinic Assessment in King Hussein Medical Centre hospital in Jordan on patient satisfaction.

Table 10: First Sub Hypothesis Test results

\begin{tabular}{|c|c|c|c|c|c|c|}
\hline Sample & Variables & $\mathrm{R}$ & $\left(\mathrm{R}^{2}\right)$ & $\mathrm{B}$ & $(\mathrm{T})$ & $\mathrm{Sig}$ \\
\hline $\begin{array}{c}\text { King Hussein } \\
\begin{array}{c}\text { Medical } \\
\text { Center }\end{array}\end{array}$ & $\begin{array}{c}\text { Clinic } \\
\text { Assessment }\end{array}$ & 0.627 & 0,393 & 1.185 & 7.959 & 0.000 \\
\hline
\end{tabular}

- Table No.10.Indicated that there is a statically significant impact of clinic assessment on patient satisfaction in the hospitalsince thesignificance level is (0.00)and(T)calculated value $=7.959$ and4.701 respectively which are more than the tabulated value (1.97) .

- $\quad$ Table alsodemonstrate that $\left(\mathrm{R}^{2}\right)=(0.393$ and 0.184$)$ which indicate that clinicAssessment interpret $(39.3 \%$ and $18.4 \%$ ) of the change in patient satisfaction in the hospital.

- Based on the Null hypothesis is rejected and the alternative is accepted, which means that there is a statistically significant impact at significance $(\alpha \leq 0.05)$ level of clinic Assessment in King Hussein Medical CentreHospital on patient satisfaction.

Second Sub-Hypothesis testing Results;

There is no statistically significant impact at significance level $(\alpha \leq 0.05)$ of "Instrument and Equipment Assessment"in King Hussein Medical Centre Hospital in Jordan on patient satisfaction.

Table 11: Second Sub-Hypothesis Test results;

\begin{tabular}{|c|c|c|c|c|c|c|}
\hline Sample & Variables & $\mathrm{R}$ & $\left(\mathrm{R}^{2}\right)$ & $\mathrm{B}$ & $(\mathrm{T})$ & $\mathrm{Sig}$ \\
\hline $\begin{array}{l}\text { King Hussein } \\
\text { Medical Center }\end{array}$ & $\begin{array}{c}\text { Instruments and } \\
\text { equipment } \\
\text { Assessment }\end{array}$ & 0.349 & 0.144 & 0.692 & 4.242 & 0.000 \\
\hline
\end{tabular}

- Table No.11.Indicated that there is a statically significant impact of "Instruments and equipment assessment" on patient satisfactionin the hospitalsince thesignificance level is (0.00). And T calculated value $=4.242$ and 4.274 respectively which are more than the tabulated value ( ).

- Table alsodemonstrate that $\left(\mathrm{R}^{2}\right)=(0.144$ and 0.157$)$ which indicate that "Instruments and equipment Assessment"interpret (14.4\% and $15.7 \%)$ of the change in patient satisfaction in the hospital.

- Based on theNull hypothesis is rejected and the alternative is accepted whichmeans that there is a statistically significant impact at significance $(\alpha \leq 0.05)$ level of "Instruments and equipment Assessment" in King Hussein Medical Centreon patient satisfaction.

\section{Third Sub-Hypothesis testing Results}

There is no statistically significant impact at significance $(\alpha \leq 0.05)$ level of nursing Assessment inKing Hussein Medical Centrehospital on Patient Satisfaction.

Table 12: Third Sub-Hypothesis Test results

\begin{tabular}{|c|c|c|c|c|c|c|}
\hline Sample & Variables & $\mathrm{R}$ & $\left(\mathrm{R}^{2}\right)$ & $\mathrm{B}$ & $(\mathrm{T})$ & $\mathrm{Sig}$ \\
\hline $\begin{array}{c}\text { King Hussein } \\
\text { Medical Center }\end{array}$ & $\begin{array}{c}\text { Nursing } \\
\text { Assessment }\end{array}$ & 0.552 & 0.305 & 0.674 & 6.554 & 0.000 \\
\hline
\end{tabular}

- Table No.12. indicated that there is a statically significant impact of nursing assessment on patient satisfaction in the hospitalsince thesignificance level is $(0.00)$ and $\mathrm{T}$ calculated value $=86.554$ and 4.597 respectively which are more than the tabulated value ( )

- Table alsodemonstrate that $\left(\mathrm{R}^{2}\right)=(0.305$ and 0.421$)$ which indicate that nursingassessment interpret $(30.5 \%$ and $17.7 \%$ ) of the change in patient satisfaction in the hospital.

- Based on the Null hypothesis is rejected and the alternative is accepted which means that there is a statistically significant impact at significance $(\alpha \leq 0.05)$ level of nursing assessment in King Hussein Medical CentreHospital on patient satisfaction.

\section{Fourth sub - hypothesis testing Results}

- There is no statistically significant impact at significance $(\alpha \leq 0.05)$ level of Physician Assessment in King Hussein Medical CentreHospital on patient satisfaction

Table No.13.Fourth Sub Hypothesis Test results

\begin{tabular}{|c|c|c|c|c|c|c|}
\hline Sample & Variables & $\mathrm{R}$ & $\left(\mathrm{R}^{2}\right)$ & $\mathrm{B}$ & $(\mathrm{T})$ & Sig \\
\hline $\begin{array}{c}\text { King Hussein } \\
\text { Medical Centre }\end{array}$ & $\begin{array}{c}\text { Physician } \\
\text { Assessment }\end{array}$ & 0.652 & 0.425 & 1.268 & 8.510 & 0.000 \\
\hline
\end{tabular}

- Table No.13. Indicated that there is a statically significant impact of physician assessment on patient satisfaction in the hospital since thesignificance level is $(0.00), \mathrm{T}$ calculated value $=8.521$ and6.228 respectively which are more than the tabulated value ( ).

- Table alsodemonstrate that $\left(\mathrm{R}^{2}\right)=(0.425$ and 0.284$)$ which indicate that physicianassessment interpret $(42.5 \%$ and $28.4 \%$ ) of the change in patient satisfaction in the hospital.Based on the null hypothesis is rejected and the alternative is accepted, which means that there is a statistically significant impact at significance $(\alpha \leq 0.05)$ level of Physician Assessment in King Hussein Medical CentreHospital on patient satisfaction.

\section{Second Main Hypothesis}

There are no statistically differences of impactof servicequality on patient satisfaction due to their demographic data (gender, age, and education level,)

Table 14

\begin{tabular}{|c|c|c|c|c|}
\hline Sample & Variable & F Tabulated & F Calculated & Sig*** \\
\hline $\begin{array}{c}\text { King Hussein } \\
\text { Medical Centre }\end{array}$ & Gender & 2.04 & 6.023 & 0 \\
\hline
\end{tabular}

\section{Volume 6 Issue 12, December 2017}




\section{International Journal of Science and Research (IJSR) \\ ISSN (Online): 2319-7064}

Index Copernicus Value (2016): 79.57 | Impact Factor (2015): 6.391

\begin{tabular}{|c|c|c|c|c|}
$\begin{array}{c}\text { King Hussein } \\
\text { Medical Centre }\end{array}$ & Age & 1.8 & 6.079 & 0 \\
\hline $\begin{array}{c}\text { King Hussein } \\
\text { Medical Centre }\end{array}$ & $\begin{array}{c}\text { Education } \\
\text { Level }\end{array}$ & 2.16 & 10.097 & 0 \\
\hline
\end{tabular}

- Table No.14. Indicates that F calculated values are more than $\mathrm{F}$ tabulated values for all demographic variables in the sample, this means that there are statistically significant differences at $(\alpha \leq 0.05)$ level in impact of quality on patient satisfaction in the hospital due to ( gender, age, and educational level)

Data analysis indicated the following results:

- Health Service quality has an impact of patient satisfaction.

- Clinic assessment as one of health quality dimension has an impact patient satisfactions.

- Instruments and equipment assessment as one of health quality dimension has an impact on patient satisfaction.

- Nursing assessment as one of health quality dimension has an impact on patient satisfaction.

- Physician assessment as one of health quality dimension has an impact on patient satisfaction.

- There are differences in the impact of quality on patient satisfaction due to demographic variables (gender, age, and education level).

\section{Conclusion \& Recommendations}

The study results revealed that quality of care has an impact on patient satisfaction. Moreover the results indicated that patients are satisfied with quality of care in the two hospitals. The questionnaire is proven to be reliable and consistent and is useful as an option for policy makers to ensure that hospital services meet patient needs. The findings provide important insight on developing tools to measure patient experience for improving the quality of care and laying the foundation for further research into patient expectations and needs regarding The findings provided important insight on developing tools to measure patient experience in hospitals to improve the quality of care and to lay the foundation for further research on patient expectations and needs.

On the light of the results mentioned above, the researcher suggests the following recommendations

- The hospital have to set up criteria for their quality provided for patients.

- Hospital are requested to provide sufficient number of qualifies medical staff to deal with the increased number of patients.

- Hospitals should aware all of their staff either medical or managerial ones with the advantages of quality.

- Hospital shouldestablish quality culture among medical and managerial staff through seminars and training programs.

- Hospitals should carry out periodical studies regarding patient ratification to know the weakness points in order to avoid or to adjust.

\section{Future Research}

There is a bad need for conducting suchresearch witha different sample and different hospitals such making the comparison between private and public hospitals.

\section{References}

[1] Greer, S.L., 2004. Territorial politics and health policy: UK health policy in comparative perspective. Manchester University Press.Leung, A.K. and Robson, W.L.M., 2007. Febrile seizures. Journal of Pediatric Health Care, 21(4), pp.250-255.

[2] Bonfrer, I., Van de Poel, E., Grimm, M. and van Doorslaer, E., 2012. Does health care utilization match needs in Africa? Challenging conventional needs measurement.

[3] Aiken, L.H., Sermeus, W., Van den Heede, K., Sloane, D.M., Busse, R., McKee, M., Bruyneel, L., Rafferty, A.M., Griffiths, P., Moreno-Casbas, M.T. and Tishelman, C., 2012. Patient safety, satisfaction, and quality of hospital care: cross sectional surveys of nurses and patients in 12 countries in Europe and the United States. Bmj, 344, p.e1717.

[4] Bensing J. Doctor-patient communication and the quality of care. Social science \& medicine. 1991 Dec 31; 32(11):1301-10.

[5] van Campen, C., Sixma, H., Friele, R.D., Kerssens, J.J. and Peters, L., 1995. Quality of care and patient satisfaction: a review of measuring instruments. Medical Care Research and Review, 52(1), pp.109-133.

[6] Wolf, D.M., Lehman, L., Quinlin, R., Zullo, T. and Hoffman, L., 2008. Effect of Patient-Centered Care on Patient Satisfaction and Quality of Care. Journal of nursing care quality, 23(4), pp.316-321.

[7] Andaleeb, S.S., 2001. Service quality perceptions and patient satisfaction: a study of hospitals in a developing country. Social science \& medicine, 52(9), pp.13591370 .

[8] Marquis, M.S., Davies, A.R. and Ware Jr, J.E., 1983. Patient satisfaction and change in medical care provider: a longitudinal study. Medical Care, pp.821-829.

[9] Zastowny, T.R., Stratmann, W.C., Adams, E.H. and Fox, M.L., 1995. Patient satisfaction and experience with health services and quality of care. Quality Management in Healthcare, 3(3), pp.50-61.

[10]Zineldin, M., 2006. The quality of health care and patient satisfaction: an exploratory investigation of the 5Qs model at some Egyptian and Jordanian medical clinics. International Journal of Health Care Quality Assurance, 19(1), pp.60-92.

[11] Hjortdahl, P. and Laerum, E., 1992. Continuity of care in general practice: effect on patient satisfaction. Bmj, 304(6837), pp.1287-1290.

[12] Badri, M.A., Attia, S. and Ustadi, A.M., 2009. Healthcare quality and moderators of patient satisfaction: testing for causality. International journal of health care quality assurance, 22(4), pp.382-410

[13] Aagja, J.P. and Garg, R., 2010. Measuring perceived service quality for public hospitals (PubHosQual) in the Indian context. International Journal of Pharmaceutical and Healthcare Marketing, 4(1), pp.60-83.

\section{Volume 6 Issue 12, December 2017}




\section{International Journal of Science and Research (IJSR) \\ ISSN (Online): 2319-7064 \\ Index Copernicus Value (2016): 79.57 | Impact Factor (2015): 6.391}

[14]Esch, B.M., Marian, F., Busato, A. and Heusser, P., 2008. Patient satisfaction with primary care: an observational study comparing anthroposophic and conventional care. Health and Quality of Life

Outcomes, 6

[15] Uma Sekaran .research methods .2012

Appendices: 1 Patient satisfaction Questionnaire in ENT Clinic

\begin{tabular}{|c|c|c|c|c|c|c|}
\hline \multirow{2}{*}{$\begin{array}{l}\text { Num } \\
1 \\
\end{array}$} & \multicolumn{6}{|l|}{ Question } \\
\hline & \multicolumn{6}{|c|}{ What is your age? 18 to $24 \quad \square \quad 25$ to $34 \quad \square \quad 35$ to $44 \quad \square \quad 45$ to $54 \quad \square \quad 55$ or older $\square$} \\
\hline \multicolumn{7}{|c|}{2 What is degree you have received? } \\
\hline \multicolumn{7}{|c|}{ Less than high school $\square \quad$ High school $\quad \square \quad$ Bachelor degree $\square \quad$ Graduate degree $\quad \square$ Higher Degree $\square$} \\
\hline & Please put $(\sqrt{ })$ in front of chosen answer & $\begin{array}{c}\text { Strongly Disagree } \\
1\end{array}$ & $\begin{array}{l}\text { Disagree } \\
2\end{array}$ & $\begin{array}{c}\text { Neutral } \\
3\end{array}$ & $\begin{array}{c}\text { Agree } \\
4\end{array}$ & $\begin{array}{c}\text { Strongly Agree } \\
5\end{array}$ \\
\hline \multicolumn{7}{|c|}{ Clinic Assessment } \\
\hline 3 & Clinic Location Accessible\&Convenient & & & & & \\
\hline 4 & Clinic Is Clean \& Tidy & & & & & \\
\hline 5 & Sufficient \& Comfortable Clinic furniture & & & & & \\
\hline 6 & Clinic Information \&Appointment Desk was helpful & & & & & \\
\hline 7 & Easy access to patient old medical reports & & & & & \\
\hline 8 & Warm reception and tact in dealing with patient & & & & & \\
\hline \multicolumn{7}{|c|}{ Instrument \&Equipments Assessment in the clinic } \\
\hline 9 & Clinic has All Necessary Instrument & & & & & \\
\hline 10 & Clinic Is Well Equipped & & & & & \\
\hline 11 & Clean \& hygienic instrument & & & & & \\
\hline \multicolumn{7}{|c|}{ Nursing assessment } \\
\hline 12 & Nursing Staff was cooperative & & & & & \\
\hline 13 & Nursing Staff are competent & & & & & \\
\hline 14 & Nursing Staff are Skilled & & & & & \\
\hline \multicolumn{7}{|c|}{ Doctors assessment } \\
\hline 15 & Doctors Behave well with the patient & & & & & \\
\hline 16 & Doctor shows Respect for what patient want to say & & & & & \\
\hline 17 & Doctor was able to diagnose patient case & & & & & \\
\hline 18 & Patient get enough time with doctor & & & & & \\
\hline 19 & Patient Privacy Well Maintained & & & & & \\
\hline 20 & $\begin{array}{l}\text { Doctor were able to give proper management to Patient } \\
\text { Case }\end{array}$ & & & & & \\
\hline 21 & Doctors are well Qualified & & & & & \\
\hline \multicolumn{7}{|c|}{ patient satisfaction assessment } \\
\hline 22 & I was overall satisfied with the treatment & & & & & \\
\hline 23 & I would recommend this clinic to my Relative \& Friends & & & & & \\
\hline 24 & $\begin{array}{l}\text { Overall, the service you received from the staff at clinic } \\
\text { considered good }\end{array}$ & & & & & \\
\hline
\end{tabular}

Volume 6 Issue 12, December 2017 www.ijsr.net 